\title{
Relation of regional echo amplitude to left ventricular function and the electrocardiogram in left ventricular hypertrophy
}

\author{
L M SHAPIRO, R B MOORE, R B LOGAN-SINCLAIR, D G GIBSON \\ From the Department of Cardiology and Medical Electronics, Brompton Hospital, London
}

SUMMARY In order to determine the relation between three manifestations of left ventricular hypertrophy-ST-T wave changes on the electrocardiogram, diastolic disturbances, and increased myocardial echo intensity- $M$ mode and cross sectional echocardiograms were recorded in 12 normal subjects, 15 athletes, 16 patients with hypertrophic cardiomyopathy, and 42 patients with secondary left ventricular hypertrophy due to aortic stenosis (20), severe essential hypertension (8), coarctation (7), or subaortic stenosis (7). M mode echocardiograms were digitised and cross sectional echocardiograms were analysed for regional echo intensity. In patients with hypertrophy regional echo amplitude was significantly increased in mid and basal septum and posterior left ventricular wall. Patients with increased echo amplitude in any region showed a higher incidence of ST-T wave abnormalities than those without and of diastolic abnormalities-including prolongation of isovolumic relaxation time, delay in mitral valve opening with respect to minimum cavity dimension, and a reduction in peak rate of posterior wall thinning and dimension increase. There was a significant rank order correlation between median pixel count and these diastolic abnormalities. No significant differences were demonstrable in these relations between the diagnostic groups. By contrast, electrocardiographic findings, diastolic function, and pixel count were uniformly normal in athletes, although the increase in left ventricular mass was similar to that in the patients.

Thus an increase in left ventricular mass alone is not responsible for repolarisation or wall motion abnormalities occurring in pathological left ventricular hypertrophy. These latter changes are, however, strongly associated with the change in myocardial properties detected as an increase in echo intensity and may be due to increased interstitial fibrosis.

Concentric left ventricular hypertrophy may occur in athletes, as the result of pressure overload, or in the absence of any clear underlying cause, in hypertrophic cardiomyopathy. The increased left ventricular mass is frequently associated with repolarisation disturbances on the electrocardiogram and abnormal diastolic function. ${ }^{1-3}$ In addition, an increase in myocardial echo intensity has also been found in patients with left ventricular hypertrophy due to valvular heart disease. ${ }^{4}$ The clinical significance of this alteration in the physical properties of the myocardium is not clear, although its presence has been related to increased myocardial collagen content. ${ }^{5}$

Requests for reprints to Dr L M Shapiro, National Heart Hospital, London W1M 8BA.

Accepted for publication 8 March 1984
The purpose of the present study was to examine the relative incidence of regional myocardial echo amplitude and other clinical manifestations in a large series of patients with hypertrophy of various types in order to determine possible interrelations between them.

\section{Patients and methods}

\section{STUDY POPULATION}

$M$ mode and cross sectional echocardiograms were recorded on 12 normal subjects aged from 23 to 46 years (seven men and five women) and in 73 subjects with concentric left ventricular hypertrophy. These latter were selected to include only those with an increase in left ventricular muscle mass greater than the $95 \%$ confidence limit of normal. No patient with 
significant valvular regurgitation, or exertional chest pain was included. Forty of these subjects were $>40$ years of age, two of whom were athletes. Of these, 14 underwent coronary arteriography which showed no more than minor arterial narrowing. None of the remaining patients had significant $Q$ wave changes on the electrocardiogram or significant regional disturbances of wall motion on cross sectional echocardiography.

The group with left ventricular hypertrophy included: (a) 15 top class athletes ${ }^{6}$ actively engaged in a number of sporting activities including swimming (6), running (5), canoeing (2), and judo (2), all but two of whom were men (age range 21-44 years); (b) 16 patients with hypertrophic cardiomyopathy, diagnosed from the typical clinical, echocardiographic, and angiographic features ${ }^{7}$ (age range 12-57 years, nine men, seven women); (c) 15 patients with coarctation of the aorta or severe essential hypertension (systolic blood pressure $>185 \mathrm{~mm} \mathrm{Hg}$, age range 6 months to 67 years); and (d) 27 patients (17 men, 10 women) with severe left ventricular outflow tract obstruction requiring surgery, including 20 with aortic valve stenosis and seven with fixed subvalvular aortic stenosis (age range 9-63 years).

\section{ECHOCARDIOGRAPHY}

Cross sectional echocardiograms were recorded with an ATL Mark III mechanical sector scanner, using a 3.5 $\mathrm{MHz}$ transducer. Although all standard views were recorded when possible, estimates of myocardial echo amplitude were made from parasternal long axis views. The master gain setting was standardised for this view to the lowest value at which the parietal pericardium posterior to the left ventricle appeared as a continuous line at the highest level of pixel intensity (white on the display). Echocardiographic images were recorded on 0.75 inch $(2 \mathrm{~cm})$ video tape, using a Sony U-matic recorder (VO 2631).

\section{Image analysis}

Regional echo amplitude was demonstrated in real time using a Brompton Encoder. ${ }^{4}$ Seven grey scale levels were used, the lowest as cyan (one) rising through green, yellow, red, magenta, blue, and white (seven). End diastolic stop frames were displayed using a tape recorder with digital frame advance (Sony 5800 PS). Four areas of interest were identified on each: mid and basal septum and mid and basal posterior wall, corresponding to the nomenclature of Edwards et $a l,{ }^{8}$ using an interactive system. These areas were limited to myocardium, care being taken not to include endocardial or epicardial echoes. Approximately 300 individual picture elements (pixels) were included in each region, whose individual amplitudes were displayed as a histogram. The rela- tive height of each column was derived from a separate digital readout, and the median pixel intensity for each region was derived.

\section{MODE ECHOCARDIOGRAPHY}

$M$ mode echocardiograms were recorded with simultaneous electrocardiograms and phonocardiograms in the semi-left lateral position at a paper speed of 100 $\mathrm{mm} / \mathrm{s}$. They were recorded at the level of the tips of the mitral leaflets to define the timing of mitral valve opening, and all showed clear continuous echoes from both surfaces of the septum and posterior wall. The thickness of the septum and posterior wall was measured from their leading edges at the time of onset of the $Q$ wave of the electrocardiogram (end diastole). The timing of aortic valve closure was taken as the onset of the first high frequency vibration of the aortic component of the second heart sound and isovolumic relaxation as the time intervals between this and the initial separation of mitral cusp leaflets.

\section{MEASUREMENTS}

Echocardiograms were digitised ${ }^{9}$ and the following measurements made: (a) RR interval; (b) maximum (Dd) and minimum (Ds) left ventricular dimension; (c) peak rate of increase of dimension during early diastole $(\mathrm{cm} / \mathrm{s}) ;(d)$ peak rate of fall of dimension during ejection, normalised to unit dimension (peak $\mathrm{VCF}$, per s); and (e) isovolumic relaxation time and the interval from minimum cavity dimension to mitral opening. Minimum cavity dimension was identified as the time that the first derivative dimension crossed the baseline, from negative to positive.

Fractional shortening was derived as (Dd-Ds)/Dd. Since all equations proposed give proportionate results, the simple "cube" formula was used to calculate left ventricular mass as: mass $=1.055$ ([VS + PW + Dd] $3-D d 3$ ), where VS and PW are septal and posterior wall thickness.

\section{ELECTROCARDIOGRAPHIC ANALYSIS}

Standard 12 lead electrocardiograms were recorded within 48 hours of the echocardiogram. For the purposes of the study the electrocardiogram was considered abnormal if ST depression ( $\geqslant 1 \mathrm{~mm}$ ) or T wave inversion in anterior or lateral leads was present. $Q R S$ voltage changes were not analysed.

\section{STATISTICAL METHODS}

The measurements of the $M$ mode and cross sectional echocardiogram and the electrocardiogram were made independently and by separate observers. Median pixel intensity was calculated from a mean of three histograms; the variability of this method and that for $M$ mode digitisation has been previously reported. 4 Values are quoted as mean with one standard devia- 
tion (SD). Mann-Whitney $U$ and $\chi^{2}$ tests were used to test differences between variables. Spearman's rank order correlation coefficients were calculated (rho).

\section{CRITIQUE OF METHODS}

Measurement of left ventricular mass-Estimates of left ventricular mass were based on M mode echocardiographic measurements of wall thickness and cavity size. It is thus possible that they were subject to the well known limitations of this technique and, in particular, may have been in error in patients with hypertrophic cardiomyopathy in whom cavity shape was abnormal. For this reason, we did not use them to determine its exact degree but merely to document its presence in a group of patients with conditions in which hypertrophy is characteristically present. We feel, therefore, that minor errors in the quantification of its extent resulting from $M$ mode determinations do not significantly affect our conclusions.

Coronary artery disease-Patients were excluded from the study if there was clinical or electrocardiographic evidence of coronary artery disease. Coronary arteriography had not, however, been performed in all patients so that clinically silent disease cannot be excluded. Nevertheless, this lack was probably unimportant. Diastolic abnormalities of coronary artery disease are quite different from those of left ventricular hypertrophy and were not seen in any of the patients. The same applies to the pattern of distribution of myocardial fibrosis, which is patchy in coronary artery disease, whereas the abnormalities of echo amplitude observed in the present study were generalised. Finally, subendocardial ischaemia has been invoked as a pathogenic mechanism in severe hypertrophy even in the absence of large vessel obstruction so that this entity cannot be rigorously excluded even when a coronary arteriogram is normal.

\section{Results}

\section{LEFT VENTRICULAR CAVITY SIZE AND WALL \\ THICKNESS}

Maximum and minimum values of left ventricular dimension were normal in all patient groups except those with hypertrophic cardiomyopathy, in which both were reduced (Table 1). In addition, there was significant enlargement of cavity size in the athletes. By definition, posterior wall thickness was significantly increased in all patients included in the study, resulting in significant increases in left ventricular mass.

\section{MYOCARDIAL ECHO INTENSITY}

Median values of myocardial echo intensity were low in normal subjects, but in spite of this consistently higher values were recorded from the septum than from the posterior wall. Although left ventricular muscle mass was considerably increased in the athletes, median pixel intensity was uniformly normal in all four regions in these subjects (Figure a). By contrast, values were significantly greater in patients with left ventricular hypertrophy due to outflow tract obstruction, hypertension, or hypertrophic cardiomyopathy (Figure b). There were no significant differences between values recorded in the different diagnostic groups, and in particular values from the septum of the patients with hypertrophic cardiomyopathy were no different from those in patients with secondary left ventricular hypertrophy. In all groups, however, significantly lower intensities were recorded from the posterior wall than from the septum.

\section{ELECTROCARDIOGRAM}

These were uniformly normal with respect to ST-T wave changes in the normal group and also in the athletes, although in some of the latter the voltage criteria for left ventricular hypertrophy were fulfilled. By contrast, an abnormal electrocardiogram was present in $47 \%$ of patients with hypertension, $75 \%$ of those with left ventricular outflow tract obstruction, and $88 \%$ of those with hypertrophic cardiomyopathy.

\section{LEFT VENTRICULAR FUNCTION}

Systolic left ventricular function, measured by peak normalised rate of dimension fall (peak VCF) and fractional shortening, was within normal limits in all groups (Table 2). Diastolic function, assessed from the duration of isovolumic relaxation time and peak rates of dimension increase and posterior wall thin-

Table 1 Median pixel count in subjects with left ventricular $(L V)$ hypertrophy and control subjects. Values are mean (1SD)

\begin{tabular}{|c|c|c|c|c|c|}
\hline$L V$ dimensions & $\begin{array}{l}\text { Hypertension } \\
(n=15)\end{array}$ & $\begin{array}{l}L V \text { outflow obstruction } \\
(n=27)\end{array}$ & $\begin{array}{l}\text { Hypertrophic } \\
\text { cardiomyopathy } \\
(n=16)\end{array}$ & $\begin{array}{l}\text { Athletes } \\
(n=15)\end{array}$ & $\begin{array}{l}\text { Normal subjects } \\
(n=12)\end{array}$ \\
\hline $\begin{array}{l}\text { Posterior wall } \\
\text { Basal } \\
\text { Mid } \\
\text { Sentum }\end{array}$ & $\begin{array}{l}0.93(0.3) \\
0.89(0.4)^{\star \star}\end{array}$ & $\begin{array}{l}1.3(0.6)^{\star} \\
1.28(0.6)^{\star}\end{array}$ & $\begin{array}{l}1.1(0.4)^{\star \star} \\
1.23(0.4)^{\star}\end{array}$ & $\begin{array}{l}0.6(0.1) \\
0.57(0.1)\end{array}$ & $\begin{array}{l}0.7(0.2) \\
0.62(0.1)\end{array}$ \\
\hline $\begin{array}{l}\text { Septum } \\
\text { Basal } \\
\text { Mid }\end{array}$ & $\begin{array}{l}1.64(0.5)^{\star \star} \\
1.4(0.6)^{\star}\end{array}$ & $\begin{array}{l}1.87(0.5)^{\star} \\
1.8(0.6)^{\star}\end{array}$ & $\begin{array}{l}1.7(0.5)^{\star} \\
1.8(0.7)^{\star \star}\end{array}$ & $\begin{array}{l}0.9(0.3) \\
1.0(0.4)\end{array}$ & $\begin{array}{l}1 \cdot 1(0.2) \\
1.1(0.3)\end{array}$ \\
\hline
\end{tabular}

Difference from normal ${ }^{\star} p<0.001,{ }^{\star \star} \mathrm{p}<0.05$. 

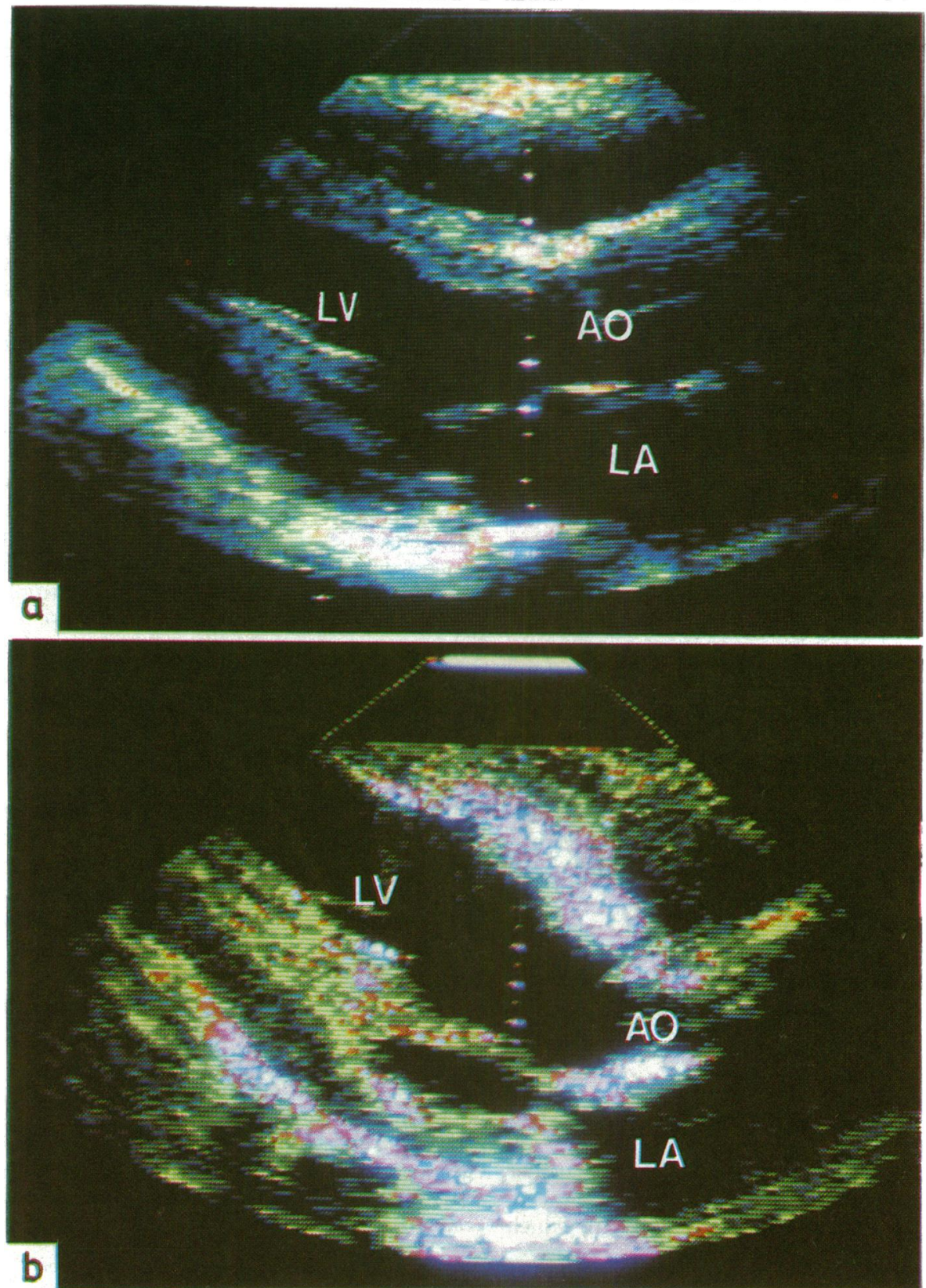

Figure Long axis parasternal echocardiographic views of (a) a 26 year old swimmer with left ventricular hypertrophy and normal echo amplitude (posterior wall myocardium shown as green and ventricular septum as predominantly green); and (b) of a patient with left ventricular hypertrophy secondary to aortic stenosis showing abnormally increased echo amplitude (yellow, red, and white) in the posterior wall and septum. $A O$, aorta; $L A$, left atrium; $L V$, left ventricle.

ning, was normal in all the athletes. Significant abnormalities were, however, present in the patients, with prolongation of isovolumic relaxation time and reduction in rates of thinning and dimension increase.
In patients with aortic stenosis the timing of aortic valve closure cannot be accurately identified, but in these patients there was delay in mitral valve opening with respect to minimum cavity dimension. 
Table 2 Left ventricular (LV) dimensions and function in subjects with hypertrophy and control subjects Values are mean (1 SD)

\begin{tabular}{|c|c|c|c|c|c|}
\hline & $\begin{array}{l}\text { Hypertension } \\
(n=15)\end{array}$ & $\begin{array}{l}L V \text { outfiow obstruction } \\
(n=27)\end{array}$ & $\begin{array}{l}\text { Hypertrophic } \\
\text { Cardiomyopathy } \\
(n=16)\end{array}$ & $\begin{array}{l}\text { Athletes } \\
(n=15)\end{array}$ & $\begin{array}{l}\text { Normal subjects } \\
(n=12)\end{array}$ \\
\hline $\begin{array}{l}\text { Dd (cm) } \\
\text { Ds (cm) } \\
\text { PW thickness (cm) } \\
\text { LV mass (g) } \\
\text { PRF (cm/s) } \\
\text { PRT (cm/s) } \\
\text { IVR (ms) } \\
\text { MDMVO (ms) } \\
\text { FS (\%) } \\
\text { Peak VCF (per s) } \\
\text { No of subjects with } \\
\text { abnormal ECG+ }\end{array}$ & $\begin{array}{c}4.6(0.5) \\
3.3(0.7) \\
1.4(0.2)^{\star} \\
352(142)^{\star \star} \\
7 \cdot 1(3)^{\star} \\
47(1.8)^{\star} \\
89(22)^{\star \star} \\
47(56)^{\star \star} \\
29(9) \\
1.7(0.6) \\
7 \star \star\end{array}$ & $\begin{array}{c}4.4(1 \cdot 1) \\
3.1(1 \cdot 1) \\
1.5(0.3)^{\star} \\
372(186)^{\star} \\
7.6(2 \cdot 5)^{\star} \\
4.2(1.4)^{\star} \\
\text { NA } \\
78(37)^{\star} \\
31(12) \\
1.9(0.9) \\
20^{\star}\end{array}$ & $\begin{array}{l}4.0(0.8)^{\star \star} \\
2.5(0.6)^{\star} \\
1.3(0.4)^{\star \star} \\
\mathrm{NC} \\
8.3(2.3)^{\star} \\
5.0(1.8)^{\star} \\
91(26)^{\star} \\
93(51)^{\star} \\
38(7) \\
2.5(0.6) \\
14^{\star}\end{array}$ & $\begin{array}{l}5.6(0.4)^{\star} \\
4.3(0.6) \\
1.3(0.1)^{\star} \\
413(79)^{\star} \\
17(3)^{\star} \\
9.6(1.3) \\
63(8) \\
8(5) \\
28(5) \\
2.8(0.4)^{\star \star} \\
0\end{array}$ & $\begin{array}{c}4.7(0.3) \\
3.1(0.4) \\
1.0(0.1) \\
208(52) \\
13(2) \\
9(1.7) \\
56(8) \\
12(9) \\
34(6) \\
2.2(0.5) \\
0\end{array}$ \\
\hline
\end{tabular}

†As defined in methods.

Difference from normal $\star p<0.001, \star \star p<0.05$.

NC, not calculated; NA, not available; Dd, diastolic dimension; Ds, systolic dimension; PW, posterior wall; PRF, peak rate of dimension increase; PRT, peak rate of wall thinning; IVR, isovolumic relaxation; MDMVO, interval from minimum dimension to mitral valve opening FS, fractional shortening; VCF, rate of shortening.

Table 3 Relation of normal or increased regional echo amplitude to left ventricular function and the electrocardiogram in patients with hypertrophy. Values are mean (1SD).

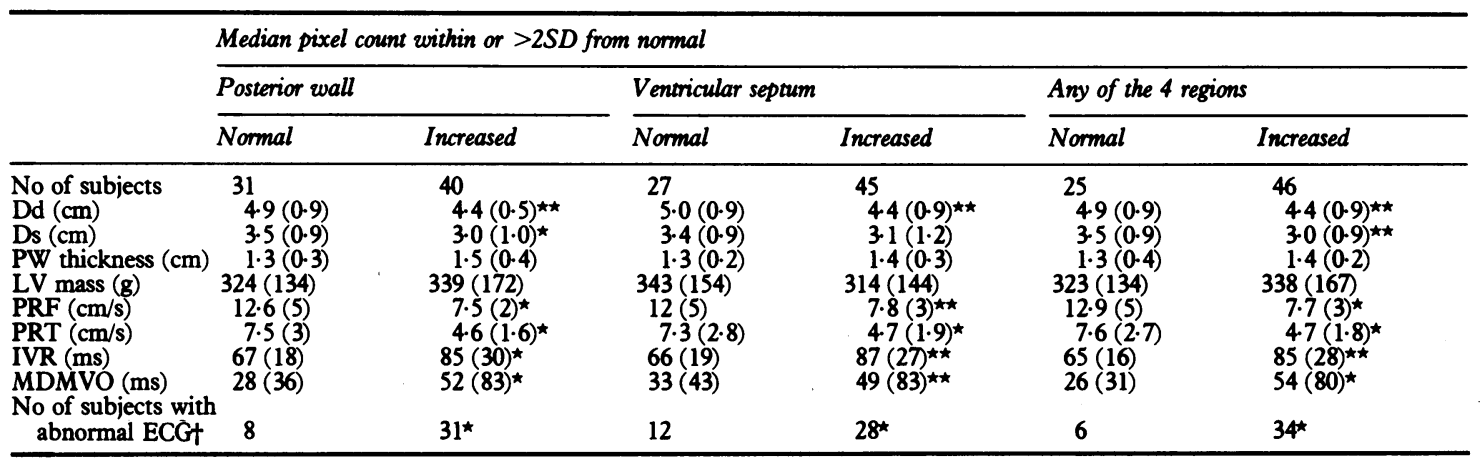

tAs defined in methods.

Differences between pairs of values: ${ }^{\star} p<0.001,{ }^{\star} \mathrm{p} p<0.05$.

Abbreviations as in Table 2.

\section{INTERRELATIONS BETWEEN ABNORMALITIES}

Relation between echo amplitude and electrocardiogram-The patients with increased echo amplitude involving any of the four regions of myocardium studied had a significantly higher $(p<0.001)$ incidence of ST-T wave abnormalities on the electrocardiogram than those in whom it was normal.

Echo amplitude and diastolic abnormalitiesDiastolic function in patients with left ventricular hypertrophy and normal echo amplitude in all four regions was compared with that in patients in whom it was increased in one or more regions (Table 3). Those with normal echo amplitude had significantly greater peak rate of wall thinning and dimension increase and a shorter isovolumic relaxation time than those in whom it was increased. There was a significant rank order between median pixel count in each of the four regions and the peak rate of wall thinning
$($ rho $=-0.54,-0.47,-0.55,-0.47)$ and the peak rate of cavity dimension increase (rho $=-0.5,-0.4$, $-0.55,-0.46)$ for basal and mid septum and basal and mid posterior wall respectively (all $p<0.001$ ). For isovolumic relaxation, the corresponding figures were $0.31,0.36,0.39,0.29(\mathrm{p}<0.02$ to $\mathrm{p}<0.005)$.

\section{Discussion}

A number of manifestations of left ventricular hypertrophy have been described apart from the diagnostic abnormality of an increase in left ventricular muscle mass. Of these, the most widely recognised are changes in the electrocardiogram, particularly those associated with ventricular repolarisation. ${ }^{10}$ An increase in $Q R S$ voltage, although frequently present, is of such low specificity that we have not considered it further. " Characteristic changes in left ventricular function have also been defined. These are diastolic in 
timing and include prolongation of isovolumic relaxation time and a reduction in the peak rate of left ventricular dimension increase and in posterior wall thinning, as demonstrated by $M$ mode echocardiography, associated with a fall in relative left ventricular filling rate measured by radionuclide blood pool scanning. 121213 Hypertrophy may also be associated with abnormal myocardial structure. Fibre length is increased from a normal of $5-7 \mu \mathrm{m}$ to $20-30 \mu \mathrm{m}$, and the arrangement of muscle cells becomes abnormal. When this is associated with an increase in fibrous tissue and cell atrophy it may resemble the fibre disarray found in hypertrophic cardiomyopathy. 14-16 Finally, preliminary studies have indicated that clinically significant left ventricular hypertrophy may be associated with an increase in regional myocardial echo amplitude, detectable by quantitative echocardiography. ${ }^{45}$ It was the aim of the present study to investigate correlations and possible pathogenetic relations between these various factors. We studied left ventricular hypertrophy of three types: physiological, as occurs in athletes; primary, in hypertrophic cardiomyopathy; and secondary to hypertension, aortic stenosis, or coarctation of the aorta.

Although essential for the diagnosis, an increase in muscle mass by itself was not necessarily associated with the other features of hypertrophy. The athletes were selected to have a degree of hypertrophy similar to that seen in the patients with hypertension or aortic stenosis, and yet, in them, electrocardiograms, diastolic left ventricular function, and regional myocardial echo intensity were all within normal limits. ${ }^{6} 17$ In the remaining patients, however, a series of correlations could be defined. An increase in regional echo intensity was present in 52 of 64 with primary or secondary hypertrophy and was strongly correlated both with the presence of ST-T wave changes on the electrocardiogram and with a series of abnormalities of diastolic function. These relations were apparent within the group of patients with pathological hypertrophy alone and were independent of left ventricular mass. On the other hand, we were unable to define any difference between primary and secondary hypertrophy in terms of regional echo intensity, a finding analagous to a previous comparison between these two groups with respect to diastolic abnormalities. ${ }^{2}$ Abnormalities of echo texture have been reported in patients with hypertrophic cardiomyopathy. ${ }^{18}$ Their exact genesis is not clear, but evidence for their existence is based on examination of video tapes, the appearances having been compared to that of ground glass. Nevertheless, quantitative measurement of septal echo amplitude in patients with hypertrophic cardiomyopathy showed values indistinguishable from those seen in secondary hypertrophy, demonstrating that these appearances are not associated with any objective abnormality of regional pixel intensity.

The present observations may contribute to an understanding of the pathophysiology of left ventricular hypertrophy. They are consonant with the old idea of "physiological" versus "pathological" hypertrophy. The former, occurring in athletes, is a simple homeostatic process consisting of an increase in muscle mass only, and the latter, a more complex entity, results from disease. ${ }^{19}$ It also appears that pathological hypertrophy, as it occurs in clinical left ventricular disease, is accompanied by a change in the physical properties of myocardium that can be regularly detected by quantitative echocardiography as an increase in regional echo intensity. One possibility is that this increase is due to myocardial fibre disarray. Had this been the case particularly high values would have been expected in the septum of patients with hypertrophic cardiomyopathy, where this histological picture, although not necessarily specific, is seen in particularly well developed form. A second possibility is that raised echo amplitude is caused by increased myocardial fibrosis, characteristic of left ventricular hypertrophy occurring clinically but which may be absent in acute animal models. ${ }^{20}$ This is compatible with previous evidence suggesting that myocardial collagen content may be one factor underlying an increase in regional echo intensity in man. ${ }^{5}$ Although it is possible to suggest that abnormal myocardial structure may be the basis of the other physiological disturbances seen in left ventricular hypertrophy, such speculations are premature since our results do not allow us to distinguish association from cause. Nevertheless, clinical left ventricular hypertrophy appears a fruitful subject for investigation since it allows interactions to be studied between three fundamental properties of the myocardium-its structure, its electrical activity, and its function. In future the clinical application of already feasible technical developments in ultrasound processing and more extended clinical observations, which might include multiple observations in the same patient after the cause of the hypertrophy has been treated, will shed further light on these important questions.

\section{References}

1 Sanderson JE, Gibson DG, Brown DJ, Goodwin JF. Left ventricular filling in hypertrophic cardiomyopathy. An angiographic study. Br Heart $\mathcal{f}$ 1977; 39: 661-70.

2 Gibson DG, Traill TA, Hall RJC, Brown DJ. Echocardiographic features of secondary left ventricular hypertrophy. Br Heart $\mathcal{F}$ 1979; 41: 54-9.

3 Rykert HE, Hepburn J. Electrocardiographic abnormalities characteristic of certain cases of arterial hypertension. Am Heart $\mathcal{F}$ 1935; 10: 942-50.

4 Logan-Sinclair R, Wong CM, Gibson DG. Clinical 
application of amplitude processing of echocardiographic images. Br Heart F 1981; 45: 621-7.

5 Shaw TRD, Logan-Sinclair RB, Surin C, et al. Relation between regional echo intensity and myocardial connective tissue in chronic left ventricular disease. $\mathrm{Br} \mathrm{Heart} \mathcal{f}$ 1984; 51: 46-53.

6 Shapiro LM. Physiological left ventricular hypertrophy. Br Heart $\mathcal{F} 1984$ (in press).

7 Shapiro LM, McKenna WJ. Distribution of left ventricular hypertrophy in hypertrophic cardiomyopathy: a two-dimensional echocardiographic study. F Am Coll Cardiol 1983; 2: 437-44.

8 Edwards WD, Tajik AJ, Seward JB. Standardized nomenclature and anatomic basis for regional tomographic analysis of the heart. Mayo Clin Proc 1981; 56: $479-97$.

9 Gibson DG, Brown D. Measurement of instantaneous left ventricular dimension and filling rate in man, using echocardiography. Br Heart f 1973; 35: 1141-9.

10 Wilson FN, Macleod AG, Barker PS. The T deflection of the electrocardiogram. Trans Assoc Am Physicians 1931; 66: 29-38.

11 Bennett DH, Evans DW. Correlation of left ventricular mass determined by echocardiography with vectorcardiographic and electrocardiographic voltage measurements. Br Heart $\mathcal{f}$ 1974; 36: 981-7.

12 Traill TA, Gibson DG, Brown DJ. Study of left ventricular wall thickness and dimension changes using echo- cardiography. Br Heart f 1978; 40: 162-9.

13 Bonow RO, Rosing DR, Bacharach SL, et al. Left ventricular systolic function and diastolic filling in patients with hypertrophic cardiomyopathy. Effect of verapamil [Abstract]. Circulation 1980; 62 (suppl III): 317.

14 Moore GW, Hutchins GM, Bulkley BH, Tseng JS, Ki PF. Constituents of the human ventricular myocardium: connective tissue hyperplasia accompanying muscular hypertrophy. Am Heart $\mathcal{f}$ 1980; 100: 610-6.

15 Oldershaw PJ, Brooksby IAB, Davies MJ, Coltart DJ, Jenkings BS, Webb-Peploe MM. Correlations of fibrosis in endomyocardial biopsies from patients with aortic valve disease. Br Heart $\mathcal{F}$ 1980; 44: 609-11.

16 Anderson KR, St John Sutton MG, Lie JT. Histopathological types of cardiac fibrosis in myocardial disease. F Pathol 1979; 128: 79-85.

17 Shapiro LM, Smith RG. Effect of training on left ventricular structure and function: an echocardiographic study. Br Heart f 1983; 50: 534-9.

18 Martin RP, Rakowski H, French J, Popp RL. Idiopathic hypertrophic subaortic stenosis viewed by wide-angle phased array echocardiography. Circulation 1979; 59: 1206-17.

19 Linzbach AJ. Heart failure from the point of view of quantitative anatomy. Am $\mathcal{F}$ Cardiol 1960; 5: 370-82.

20 Frederiksen DW, Hoffnung JM, Frederiksen RT, Williams RB. The structural proteins of normal and diseased human myocardium. Circ Res 1978; 42: 459-66. 